\title{
Pullout capacity of small ground anchor: a least square support vector machine approach
}

\author{
Pijush SAMUI ${ }^{\dagger 1}$, Dookie KIM ${ }^{2}$, Bhairevi G. AIYER ${ }^{\dagger 3}$ \\ ( ${ }^{1}$ Centre for Disaster Mitigation and Management, VIT University, Vellore-632014, Tamilnadu, India) \\ ( ${ }^{2}$ Department of Civil Engineering, Kunsan National University, Kunsan, Jeonbuk, South Korea) \\ ( ${ }^{3}$ School of Mechanical and Building Science, VIT University, Vellore-632014, Tamilnadu, India) \\ †E-mail: pijush.phd@gmail.com; bhairevigaiyer94@gmail.com \\ Received Oct. 10, 2012; Revision accepted May 14, 2013; Crosschecked Feb. 25, 2015
}

\begin{abstract}
This study employs the least square support vector machine (LSSVM) for the prediction of pullout capacity of small ground anchor. LSSVM is firmly based on the theory of statistical learning and uses regression technique. In LSSVM, Vapnik and Lerner (1963)'s $\varepsilon$-insensitive loss function was replaced by a cost function which corresponded to a form of ridge regression. The input parameters of LSSVM were equivalent anchor diameter, anchor embedment depth, average cone tip resistance, average cone sleeve friction, and installation technique. Using 83 out the available $119 \mathrm{in}$-situ test datasets, an LSSVM regression model was developed. The goodness of the model was tested using the remaining 36 data points. The developed LSSVM also gave an error bar of predicted data. A sensitivity analysis was conducted to determine the effect of each input parameter. The results were compared with the artificial neural network (ANN) model. Overall, LSSVM was shown to perform well.
\end{abstract}

Key words: Artificial neural network (ANN), Least square support vector machine (LSSVM), Error bar, Ground anchor, Pullout capacity, In-situ test, Sensitivity analysis

doi: 10.1631 jzus.A1200260

Document code: A

CLC number: TU74

\section{Introduction}

Small ground anchors are often used to connect temporary light structures to the ground. The embedment length of small ground anchor is about $1 \mathrm{~m}$ and the pullout capacity is not more than a few $\mathrm{kN}$. Because of the small capacities and the temporary nature of their functions, engineers rarely put efforts into collecting engineering properties of soils for the design of small ground anchors. These constraints lead to design uncertainty even though various methods are available for determining the pullout capacity of ground anchors (Meyerhof and Adams, 1968; Vesic, 1971; Meyerhof, 1973; Das and Seeley, 1975; Das, 1978; 1980; 1987; Rowe and Davis, 1982a; 1982b;

(D) ORCID: Pijush SAMUI, http://orcid.org/0000-0001-7359-8718 (C) Zhejiang University and Springer-Verlag Berlin Heidelberg 2015
Vermeer and Sutjiadi, 1985; Murray and Geddes, 1987; Dickin, 1988; Sutherland, 1988; Koutsabeloulis and Griffiths, 1989; Rao and Kumar, 1994; Basudhar and Singh, 1994). Shahin and Jaksa (2003) initiated a different approach and paved the way for a rational design of small anchors at a nominal cost. They installed small ground anchors, measured the in-situ soil properties using only cone penetration tests, and followed that up with a pullout test on each anchor. In essence, they developed a database. Instead of trying to apply the conventional analysis, Shahin and Jaksa (2006) treated the database as containing input and output information and applied artificial neural network (ANN) as the framework for extracting the needed information. ANN used part of the data to train the building of the input-output relationship, and then validated the results by predicting the outcome for the data not used. It was found that ANN performed well for this task. By 
supplying the soil parameters and embedded length as well as the installation method, the pullout capacity, $Q$ could be predicted. However, ANN has some limitations such as black box approach, arriving at local minima, slow convergence speed, overtraining problem, and absence of probabilistic output (Park and Rilett, 1999; Kecman, 2001). In view of these deficiencies, this study looked into an alternative approach to estimate $Q$ using the same database. Specifically, this study examined the potential of least square support vector machine (LSSVM) to predict $Q$ of small ground anchor. The LSSVM is a statistical learning theory which adopts a least square as a loss function (Suykens et al., 1999). It is closely related to Gaussian processes and regularization networks. It requires solving a set of only linear equations (linear programming), which is much easier and computationally very simple. It has successfully adopted to solve different problems in engineering (Tao et al., 2008; Huang et al., 2009; Deng and Yeh, 2010; Pahasa and Ngamroo, 2011).

The paper has the following aims: (1) To examine the capability of LSSVM model for prediction of $Q$ of small ground anchor; (2) To estimate the error bar of predicted data; (3) To develop an equation for prediction of $Q$ of small ground anchor; (4) To make a comparative study between LSSVM model and ANN model developed by Shahin and Jaksa (2006); (5) To do the sensitivity analysis for determining the effect of each input parameter on $Q$ of small ground anchor.

\section{Least square support vector machine}

LSSVM model is an alternate formulation of support vector machine (SVM) regression (Vapnik, 1963) proposed by Suykens et al. (2002). Consider a given training set of $N$ data points $\left\{x_{k}, y_{k}\right\}_{k=1}^{N}$ with input data $x_{k} \in \boldsymbol{R}^{N}$ and output $y_{k} \in \boldsymbol{r}$, where $\boldsymbol{R}^{N}$ is the $N$-dimensional vector space and $\boldsymbol{r}$ is the $1 \mathrm{D}$ vector space. In this study, the input parameters are equivalent anchor diameter $\left(D_{\text {eq }}\right)$, embedment depth $(L)$, average cone resistance $\left(q_{\mathrm{c}}\right)$ along the embedment depth, average sleeve friction $\left(f_{\mathrm{s}}\right)$ along the embedment depth, and installation technique (IT). Thus, $x=\left\{D_{\text {eq }}, L, q_{\mathrm{c}}, f_{\mathrm{s}}, \mathrm{IT}\right\}$. The output of the LSSVM model is pullout capacity $(Q)$ of small ground anchors.
Thus, $y=Q$. In feature space LSSVM models take the form

$$
y(x)=\boldsymbol{w}^{\mathrm{T}} \phi(x)+b
$$

where the nonlinear mapping $\phi()$ maps the input data into a higher dimensional feature space; $\boldsymbol{w}$ is an adjustable weight vector, $\boldsymbol{w} \in \boldsymbol{R}^{N} ; b$ is the scalar threshold, $b \in \boldsymbol{r}$. In LSSVM for function estimation, the following optimization problem is formulated as

$$
\begin{aligned}
& \text { Minimize: } \frac{1}{2} \boldsymbol{w}^{\mathrm{T}} \boldsymbol{w}+\gamma \frac{1}{2} \sum_{k=1}^{N} e_{k}^{2}, \\
& \text { s.t. } y(x)=\boldsymbol{w}^{\mathrm{T}} \phi\left(x_{k}\right)+b+e_{k}, k=1,2, \ldots, N,
\end{aligned}
$$

where $\gamma$ is the regularization parameter and $e_{k}$ is the error variable.

The following equation for $Q$ prediction has been obtained by solving the above optimization problem (Smola and Scholkopf, 1998; Vapnik, 1998).

$$
Q=y(x)=\sum_{k=1}^{N} \alpha_{k} K\left(x, x_{k}\right)+b
$$

where $\alpha_{k}$ is the Lagrange multiplier.

The radial basis function is used in this analysis, which is given by

$$
\begin{gathered}
K\left(x_{k}, x_{l}\right)=\exp \left\{-\frac{\left[x_{k}-x_{l}\right]\left[x_{k}-x_{l}\right]^{\mathrm{T}}}{2 \sigma^{2}}\right\}, \\
k, l=1,2, \ldots, N,
\end{gathered}
$$

where $\sigma$ is the width of radial basis function.

\section{Present analysis}

The main objective of this study is to adopt the LSSVM methodology in the problem of $Q$ prediction of small ground anchors. In an application, part of the data are used in obtaining the regression model and the rest of the data are used for validation. The former is known as the training set, the latter the test set. Previous studies have used different percentage of the available data as the training set for different problems. 
For instance, Kurup and Dudani (2002) used 63\% of the data for training; Tang et al. (2005) used $75 \%$; while Pal (2006) used 69\%. In this study, we used $70 \%$ of the data for training. That is, for 119 cases of small ground anchors, data of 83 cases (Table 1) were randomly selected as the training dataset, and the remaining data of 36 cases (Table 2) were used as the testing dataset. ANN also has a training procedure but it requires complex non-linear optimization which sometimes only reaches local minima.
In this study, each parameter was scaled between 0 and 1 before being employed in the computation. A sensitivity analysis was carried out to obtain which input parameters have more effect on $Q$. The procedure was taken from (Liong et al., 2000). The sensitivity analysis was carried out by varying each input parameter, one at a time, at a constant rate of $20 \%$. The percent change of output was calculated for the change of input parameter. The sensitivity $(S)$ of each input parameter can be calculated by

Table 1 Training dataset used in this study

\begin{tabular}{|c|c|c|c|c|c|c|c|c|c|c|c|}
\hline$D_{\text {eq }}(\mathrm{mm})$ & $L(\mathrm{~mm})$ & $q_{\mathrm{c}}(\mathrm{MPa})$ & $f_{\mathrm{s}}(\mathrm{kPa})$ & IT & $Q(\mathrm{kN})$ & $D_{\text {eq }}(\mathrm{mm})$ & $L(\mathrm{~mm})$ & $q_{\mathrm{c}}(\mathrm{MPa})$ & $f_{\mathrm{s}}(\mathrm{kPa})$ & IT & $Q(\mathrm{kN})$ \\
\hline 25.0 & 800 & 3.55 & 26.01 & 2 & 1.11 & 44.6 & 400 & 1.14 & 32.52 & 1 & 1.45 \\
\hline 25.0 & 600 & 1.65 & 52.10 & 1 & 2.47 & 44.6 & 600 & 2.67 & 13.99 & 2 & 1.10 \\
\hline 33.0 & 400 & 2.28 & 179.71 & 2 & 1.76 & 33.0 & 600 & 1.65 & 52.10 & 2 & 1.57 \\
\hline 33.0 & 800 & 2.24 & 105.1 & 2 & 2.95 & 25.0 & 600 & 3.03 & 178.26 & 2 & 2.19 \\
\hline 33.0 & 800 & 3.55 & 26.01 & 2 & 1.71 & 25.0 & 600 & 2.67 & 13.99 & 1 & 0.87 \\
\hline 44.6 & 400 & 1.66 & 40.94 & 2 & 1.96 & 25.0 & 600 & 1.49 & 41.23 & 2 & 3.11 \\
\hline 25.0 & 600 & 1.28 & 64.64 & 1 & 3.20 & 25.0 & 600 & 2.76 & 20.82 & 2 & 0.61 \\
\hline 44.6 & 600 & 1.89 & 46.83 & 1 & 1.90 & 33.5 & 400 & 1.89 & 46.83 & 1 & 2.39 \\
\hline 33.0 & 600 & 1.65 & 52.10 & 2 & 0.63 & 25.0 & 400 & 1.63 & 44.46 & 2 & 1.05 \\
\hline 25.0 & 600 & 2.67 & 13.99 & 2 & 0.53 & 44.6 & 600 & 2.28 & 179.71 & 2 & 2.39 \\
\hline 25.0 & 600 & 1.89 & 46.83 & 1 & 1.76 & 44.6 & 600 & 1.28 & 64.64 & 1 & 2.29 \\
\hline 25.0 & 600 & 1.65 & 52.10 & 2 & 0.94 & 33.0 & 600 & 2.67 & 13.99 & 2 & 0.89 \\
\hline 25.0 & 600 & 1.65 & 52.10 & 2 & 1.63 & 33.5 & 600 & 1.28 & 64.64 & 1 & 3.11 \\
\hline 25.0 & 600 & 2.20 & 87.93 & 2 & 2.18 & 25.0 & 600 & 2.20 & 87.93 & 2 & 1.98 \\
\hline 25.0 & 600 & 1.74 & 35.93 & 1 & 2.03 & 33.5 & 400 & 1.05 & 55.68 & 1 & 1.44 \\
\hline 25.0 & 600 & 2.67 & 13.99 & 2 & 0.60 & 33.0 & 800 & 1.68 & 54.35 & 2 & 2.22 \\
\hline 44.6 & 600 & 1.28 & 64.64 & 1 & 2.49 & 44.6 & 400 & 1.63 & 44.46 & 2 & 0.78 \\
\hline 44.6 & 600 & 1.74 & 35.93 & 2 & 2.95 & 33.0 & 400 & 2.12 & 17.21 & 2 & 0.56 \\
\hline 44.6 & 400 & 2.28 & 179.71 & 2 & 2.55 & 25.0 & 400 & 2.28 & 179.71 & 2 & 1.52 \\
\hline 25.0 & 600 & 1.28 & 64.64 & 1 & 2.15 & 25.0 & 600 & 1.65 & 52.10 & 1 & 1.70 \\
\hline 33.0 & 400 & 0.95 & 12.22 & 2 & 0.29 & 25.0 & 600 & 2.20 & 87.93 & 2 & 2.00 \\
\hline 25.0 & 800 & 1.27 & 70.91 & 1 & 1.69 & 25.0 & 400 & 1.66 & 40.94 & 2 & 1.35 \\
\hline 33.0 & 400 & 2.21 & 70.33 & 2 & 1.81 & 25.0 & 600 & 1.89 & 46.83 & 1 & 2.16 \\
\hline 25.0 & 600 & 2.76 & 20.82 & 1 & 1.19 & 33.5 & 600 & 1.89 & 46.83 & 1 & 1.90 \\
\hline 33.0 & 600 & 1.65 & 52.10 & 2 & 1.70 & 25.0 & 600 & 3.03 & 178.26 & 2 & 1.96 \\
\hline 25.0 & 800 & 1.68 & 54.35 & 2 & 1.33 & 44.6 & 600 & 1.65 & 52.10 & 2 & 1.90 \\
\hline 44.6 & 400 & 1.05 & 55.68 & 1 & 1.34 & 44.6 & 400 & 0.95 & 13.99 & 2 & 0.63 \\
\hline 33.0 & 800 & 1.49 & 41.23 & 2 & 2.63 & 25.0 & 600 & 1.89 & 46.83 & 1 & 2.39 \\
\hline 44.6 & 600 & 1.89 & 46.83 & 1 & 2.23 & 44.6 & 800 & 1.27 & 70.91 & 1 & 3.47 \\
\hline 25.0 & 400 & 1.05 & 55.68 & 1 & 1.06 & 33.5 & 600 & 1.89 & 46.83 & 1 & 2.24 \\
\hline 25.0 & 400 & 1.63 & 44.46 & 2 & 1.36 & 33.0 & 600 & 1.74 & 35.93 & 2 & 1.51 \\
\hline 44.6 & 600 & 3.03 & 178.26 & 2 & 3.44 & 25.0 & 600 & 1.28 & 64.64 & 1 & 1.29 \\
\hline 25.0 & 600 & 2.67 & 13.99 & 2 & 0.48 & 44.6 & 800 & 2.02 & 53.73 & 1 & 2.45 \\
\hline 25.0 & 400 & 1.66 & 40.94 & 2 & 1.25 & 25.0 & 600 & 1.74 & 35.93 & 2 & 1.66 \\
\hline 33.5 & 600 & 1.89 & 46.83 & 1 & 2.30 & 25.0 & 600 & 1.74 & 35.93 & 2 & 1.54 \\
\hline 25.0 & 400 & 2.21 & 70.33 & 2 & 1.37 & 25.0 & 600 & 1.65 & 52.10 & 1 & 0.90 \\
\hline 25.0 & 600 & 2.76 & 20.82 & 2 & 0.94 & 44.6 & 400 & 2.12 & 17.21 & 2 & 0.66 \\
\hline 44.6 & 400 & 2.21 & 70.33 & 2 & 1.65 & 25.0 & 800 & 2.24 & 105.1 & 2 & 3.17 \\
\hline 25.0 & 600 & 1.89 & 46.83 & 1 & 1.87 & 33.0 & 400 & 1.66 & 40.94 & 2 & 1.19 \\
\hline 25.0 & 800 & 1.27 & 70.91 & 1 & 2.48 & 25.0 & 600 & 2.67 & 13.99 & 2 & 0.44 \\
\hline 33.5 & 600 & 1.28 & 64.64 & 1 & 2.79 & 25.0 & 600 & 1.89 & 46.83 & 1 & 2.00 \\
\hline 33.5 & 400 & 1.14 & 32.52 & 1 & 1.18 & & & & & & \\
\hline
\end{tabular}


Table 2 Testing dataset used in this study

\begin{tabular}{cccccc}
\hline$D_{\text {eq }}(\mathrm{mm})$ & $L(\mathrm{~mm})$ & $q_{\mathrm{c}}(\mathrm{MPa})$ & $f_{\mathrm{s}}(\mathrm{kPa})$ & $\mathrm{IT}$ & $Q(\mathrm{kN})$ \\
\hline 25.0 & 600 & 1.89 & 46.83 & 1 & 2.01 \\
33.5 & 600 & 1.89 & 46.83 & 1 & 2.08 \\
25.0 & 600 & 2.67 & 13.99 & 2 & 0.35 \\
25.0 & 600 & 1.65 & 52.10 & 2 & 1.52 \\
44.6 & 600 & 1.65 & 52.10 & 2 & 1.73 \\
25.0 & 800 & 2.02 & 53.73 & 1 & 2.30 \\
25.0 & 600 & 2.20 & 87.93 & 2 & 2.09 \\
25.0 & 600 & 2.76 & 20.82 & 1 & 0.92 \\
33.0 & 600 & 2.20 & 87.93 & 2 & 2.39 \\
25.0 & 600 & 2.76 & 20.82 & 2 & 0.73 \\
25.0 & 600 & 1.74 & 35.93 & 2 & 1.73 \\
44.6 & 600 & 1.89 & 46.83 & 1 & 1.85 \\
25.0 & 600 & 1.65 & 52.10 & 2 & 1.76 \\
25.0 & 600 & 2.20 & 87.93 & 2 & 1.79 \\
44.6 & 600 & 2.20 & 87.93 & 2 & 2.31 \\
25.0 & 600 & 2.02 & 53.73 & 1 & 3.02 \\
25.0 & 600 & 2.67 & 13.99 & 1 & 0.90 \\
33.0 & 800 & 2.92 & 166.57 & 2 & 3.80 \\
25.0 & 400 & 2.20 & 87.93 & 2 & 1.88 \\
25.0 & 600 & 1.14 & 32.52 & 1 & 1.24 \\
25.0 & 400 & 2.12 & 17.21 & 2 & 0.43 \\
25.0 & 600 & 1.89 & 46.83 & 1 & 1.99 \\
25.0 & 600 & 1.65 & 52.10 & 2 & 2.42 \\
33.0 & 400 & 1.63 & 44.46 & 2 & 1.44 \\
25.0 & 600 & 2.20 & 87.93 & 1 & 2.99 \\
44.6 & 600 & 1.89 & 46.83 & 1 & 1.95 \\
33.0 & 600 & 2.76 & 20.82 & 2 & 0.96 \\
44.6 & 600 & 2.76 & 20.82 & 2 & 1.10 \\
25.0 & 600 & 1.65 & 52.10 & 2 & 2.00 \\
25.0 & 600 & 1.28 & 64.64 & 1 & 2.25 \\
25.0 & 800 & 1.27 & 70.91 & 1 & 3.06 \\
25.0 & 400 & 0.95 & 12.22 & 2 & 0.35 \\
25.0 & 400 & 1.05 & 55.68 & 1 & 1.16 \\
25.0 & 600 & 3.03 & 178.26 & 1 & 2.09 \\
25.0 & 600 & 1.28 & 64.64 & 1 & 2.09 \\
25.0 & 800 & 1.68 & 54.35 & 2 & 2.19 \\
\hline & & & & & \\
\hline
\end{tabular}

$$
S(\%)=\frac{1}{N} \sum_{j=1}^{N}\left(\frac{p}{q}\right)_{j} \times 100
$$

where $N=83$, and $p$ and $q$ are the changes in output and input, respectively.

In the present study, training, testing, and sensitivity analyses of LSSVM have been carried out using MATLAB. Fig. 1 shows the flow chart of LSSVM for the prediction of $Q$.

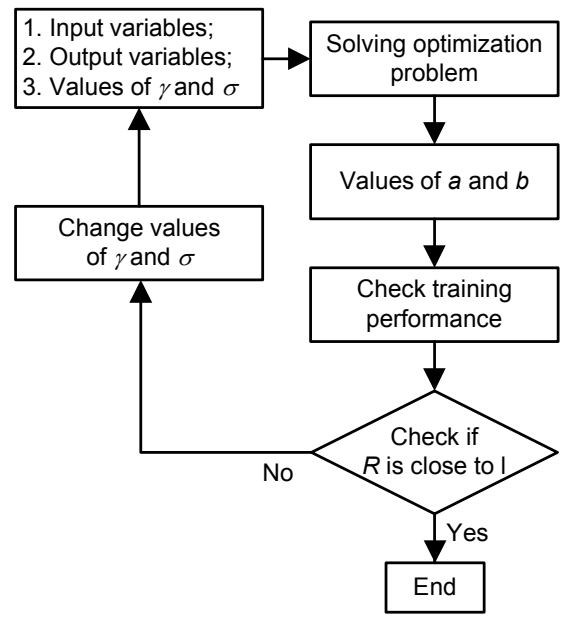

Fig. 1 Flow chart of LSSVM for the prediction of $Q$

\section{Results and discussion}

This study used coefficient of correlation $(R)$ to measure the performance of the developed LSSVM model, which is determined by

$$
R=\frac{\sum_{i=1}^{n}\left(Q_{\mathrm{a} i}-\bar{Q}_{\mathrm{a}}\right)\left(Q_{\mathrm{p} i}-\bar{Q}_{\mathrm{p}}\right)}{\sqrt{\sum_{i=1}^{n}\left(Q_{\mathrm{a} i}-\bar{Q}_{\mathrm{a}}\right)} \sqrt{\sum_{i=1}^{n}\left(Q_{\mathrm{p} i}-\bar{Q}_{\mathrm{p}}\right)}},
$$

where $Q_{\mathrm{a} i}$ and $Q_{\mathrm{p} i}$ are the actual and predicted $Q$ values, respectively, $\bar{Q}_{\mathrm{a}}$ and $\bar{Q}_{\mathrm{p}}$ are mean of actual and predicted $Q$ values corresponding to $n$ patterns. For a good model, the value of $R$ should be close to one. The values of $\gamma$ and $\sigma$ have been determined by trial and error approach. The design values of $\gamma$ and $\sigma$ are 2500 and 7, respectively. Fig. 2 depicts the performance of LSSVM model for the training dataset. It also shows that the value of $R$ is close to one. Thus, LSSVM model has successfully captured the input and output relationship. The performance of LSSVM model for the testing dataset is shown in Fig. 3. Fig. 3 confirms that the developed LSSVM model has the ability to predict $Q$ of small ground anchor. The values of root mean square error (RMSE) and variance account for (VAF) are determined for the training and testing datasets. For a good model, the values of RMSE and VAF should be 0 and $100 \%$, respectively (Erzin and Cetin, 2013). For training dataset, the 
values of RMSE and VAF are 0.2231 and $88.49 \%$, respectively. For testing dataset, the values of RMSE and VAF are 0.2596 and $88.92 \%$, respectively. Substituting $K\left(x_{i}, x\right)=\exp \left\{-\frac{\left[x_{i}-x\right]\left[x_{i}-x\right]^{\mathrm{T}}}{2 \sigma^{2}}\right\}, \quad \sigma=7$, $N=83$, and $b=-3.8239$ into Eq. (3), we can obtain:

$$
Q=\sum_{k=1}^{83} \alpha_{k} \exp \left\{-\frac{\left[x_{i}-x\right]\left[x_{i}-x\right]^{\mathrm{T}}}{98}\right\}-3.8239,
$$

which can be developed for the prediction of $Q$ based on the developed LSSVM model.

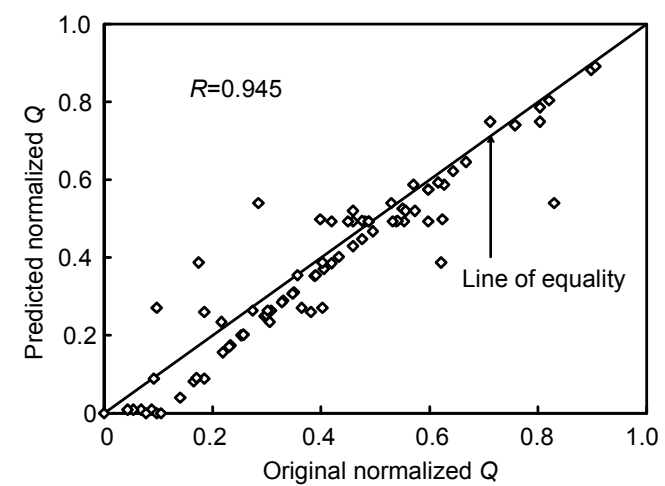

Fig. 2 Performance of training dataset

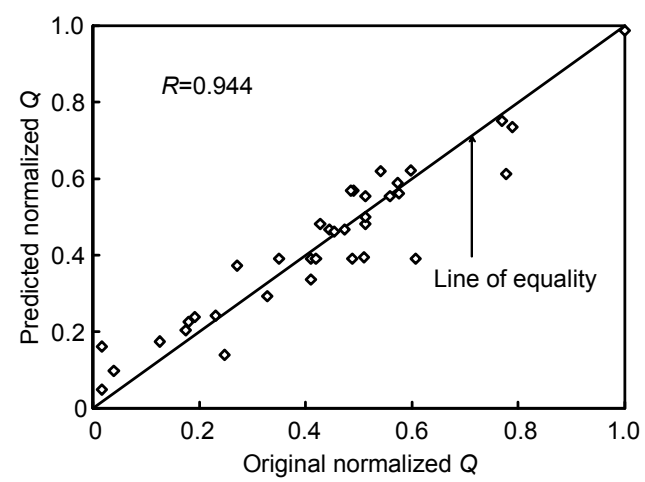

Fig. 3 Performance of testing dataset

Fig. 4 shows the value of $\alpha$ for LSSVM.

Eq. (7) can be used for the prediction of $Q$ of small ground anchor. The performances of the training and testing datasets are almost the same. Thus, the developed LSSVM model does not exhibit any overtraining. Therefore, the developed LSSVM has good generalization capability. Figs. 5 and 6 show the 95\% error bar for the training and testing datasets, respec- tively. Error bars can be used for the determination of the confidence interval. Fig. 7 shows the result of the sensitivity analysis. From Fig. 7, it is clear that $q_{\mathrm{c}}$ has the most significant effect on the predicted $Q$ followed by $f_{\mathrm{s}}, L, D_{\text {eq }}$, and IT.

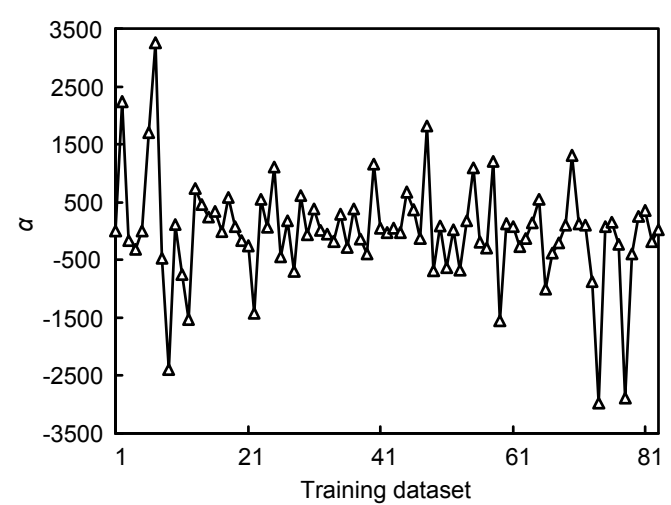

Fig. 4 Values of $\alpha$ for LSSVM

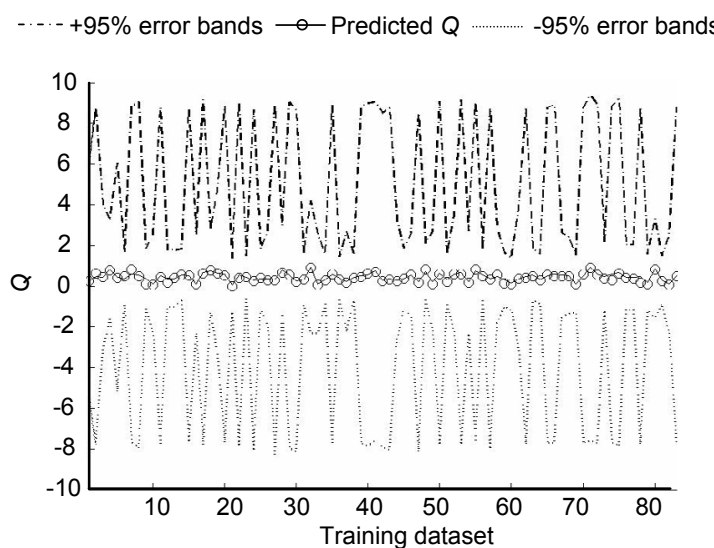

Fig. 5 95\% error bar for training dataset

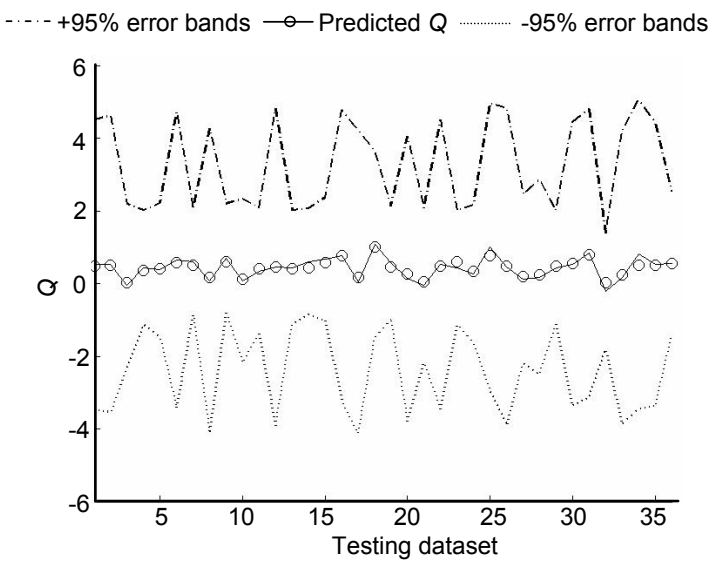

Fig. 6 95\% error bar for testing dataset 


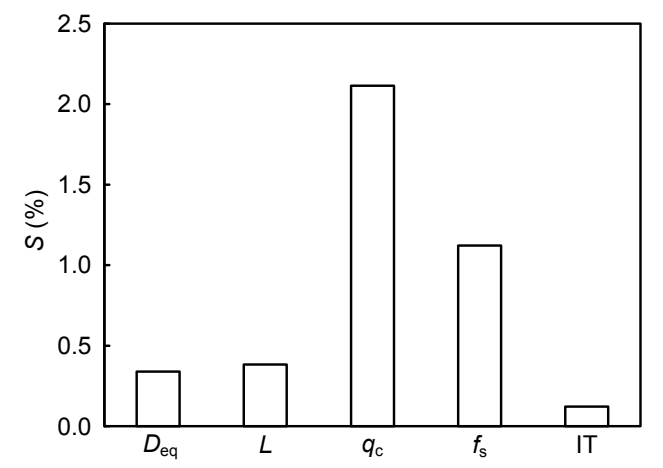

Fig. 7 Sensitivity analysis of input parameters

A comparative study has been done between the developed LSSVM model and ANN model developed by Shahin and Jaksa (2006) for testing dataset. The ANN model uses feed-forward multilayer perceptrons (MLPs) that were trained with the back-propagation algorithm. There is one hidden layer with two nodes in the ANN model. The developed ANN has a learning rate of 0.2 , a momentum term of 0.8 , hyperbolic tangent transfer function for the hidden layer nodes, and sigmoidal transfer function for the output layer node (Shahin and Jaksa, 2005). Table 3 shows the value of $R$, RMSE and mean absolute error (MAE). It is clear from Table 3 that in the present application LSSVM model performed better than Shahin and Jaksa (2006)'s ANN model. LSSVM uses only two parameters $(\gamma$ and $\sigma)$. In contrast, in ANN, there are a large number of controlling parameters, including the number of hidden layers, number of hidden nodes, learning rate, momentum term, number of training epochs, transfer functions, and weight initialization methods.

Table 3 Comparison between ANN model (Shahin and Jaksa, 2006) and LSSVM model

\begin{tabular}{cccc}
\hline Model & RMSE $(\mathrm{kN})$ & MAE $(\mathrm{kN})$ & $R$ \\
\hline ANN & 0.3971 & 0.3097 & 0.858 \\
LSSVM & 0.2596 & 0.2030 & 0.942 \\
\hline
\end{tabular}

\section{Conclusions}

This study describes an LSSVM model for the determination of $Q$ of small ground anchor. The developed LSSVM model gives promising results. The obtained error bars can be used to determine uncertainty. The performance of the developed LSSVM model is better than the ANN model. An equation is developed for the prediction of $Q$ of small ground anchor. LSSVM has the advantage that once the model is trained, it can be used as an accurate and quick tool for predicting $Q$ of small ground anchor. Sensitivity analysis indicates that $q_{\mathrm{c}}$ is the most significant input parameter for predicting $Q$ of small ground anchor. Results demonstrated that LSSVM can be a powerful and practical tool for tackling a class of problems exemplified by the determination of pullout capacities of small ground anchor as laid out herein.

\section{References}

Basudhar, P.K., Singh, D.N., 1994. A generalized procedure for predicting optimal lower bound break-out factors of strip anchors. Geotechnique, 44(2):307-318. [doi:10. 1680/geot.1994.44.2.307]

Das, B.M., 1978. Model tests for uplift capacity of foundations in clay. Soils and Foundations, 18(2):17-24. [doi:10. 3208/sandf1972.18.2_17]

Das, B.M., 1980. A procedure for estimation of ultimate uplift capacity of foundations in clay. Soils and Foundations, 20(1):77-82. [doi:10.3208/sandf1972.20.77]

Das, B.M., 1987. Developments in Geotechnical Engineering, Theoretical Foundation Engineering. Elsevier.

Das, B.M., Seeley, G.R., 1975. Breakout resistance of horizontal anchors. Journal of Geotechnology Engineering Division, ASCE, 101(9):999-1003.

Deng, S., Yeh, T.H., 2010. Applying least squares support vector machines to the airframe wing-box structural design cost estimation. Expert Systems with Applications, 37(12):8417-8423. [doi:10.1016/j.eswa.2010.05.038]

Dickin, E.A., 1988. Uplift behaviour of horizontal anchor plates in sand. Journal of Geotechnology Engineering, ASCE, 114(11):1300-1317. [doi:10.1061/(ASCE)07339410(1988)114:11(1300)]

Erzin, Y., Cetin, T., 2013. The prediction of the critical factor of safety of homogeneous finite slopes using neural networks and multiple regressions. Computer Geoscience, 51:305-313. [doi:10.1016/j.cageo.2012.09.003]

Huang, Z., Luo, J., Li, X., et al., 2009. Prediction of effluent parameters of wastewater treatment plant based on improved least square support vector machine with PSO. 1st International Conference on Information Science and Engineering (ICISE), Nanjing, No. 5454606, p.40584061.

Kecman, V., 2001. Learning and Soft Computing Support Vector Machines, Neural Networks, and Fuzzy Logic Models. The MIT Press, Cambridge.

Koutsabeloulis, N.C., Griffiths, D.V., 1989. Numerical modeling of the trap door problem. Geotechnique, 39(1): 77-89. [doi:10.1680/geot.1989.39.1.77]

Kurup, P.U., Dudani, N.K., 2002. Neural networks for 
profiling stress history of clays from PCPT data. Journal of Geotechnical and Geoenvironmental Engineering, 128(7):569-579. [doi:10.1061/(ASCE)1090-0241(2002) $128: 7(569)]$

Liong, S.Y., Lim, W.H., Paudyal, G.N., 2000. River stage forecasting in Bangladesh: neural network approach. Journal of Computing in Civil Engineering, 14(1):1-8. [doi:10.1061/(ASCE)0887-3801(2000)14:1(1)]

Meyerhof, G.G., 1973. Uplift resistance of inclined anchors and piles. Proceedings of 8th International Conference on Soil Mechanics and Foundation Engineering, Moscow, USSR, p.167-172.

Meyerhof, G.G., Adams, J.I., 1968. The ultimate uplift capacity of foundations. Canadian Geotechnical Journal, 5(4): 225-244. [doi:10.1139/t68-024]

Murray, E.J., Geddes, J.D., 1987. Uplift of anchor plates in sand. Journal of Geotechnology Engineering Division, ASCE, 113(3):202-215. [doi:10.1061/(ASCE)0733-9410 (1987)113:3(202)]

Pahasa, J., Ngamroo, I., 2011. A heuristic training-based least squares support vector machines for power system stabilization by SMES. Expert Systems with Applications, 38(11):13987-13993. [doi:10.1016/j.eswa.2011.04.206]

Pal, M., 2006. Support vector machines-based modelling of seismic liquefaction potential. International Journal for Numerical and Analytical Methods in Geomechanics, 30(10):983-996.

Park, D., Rilett, L.R., 1999. Forecasting freeway link ravel times with a multi-layer feed forward neural network. Computer Aided Civil and Infrastructure Engineering, 14:358-367.

Rao, K.S.S., Kumar, J., 1994. Vertical uplift capacity of horizontal anchors. Journal of Geotechnology Engineering, ASCE, 120(7):1134-1147. [doi:10.1061/(ASCE)07339410(1994)120:7(1134)]

Rowe, R.K., Davis, E.H., 1982a. The behaviour of anchor plates in clay. Geotechnique, 32(1):9-23. [doi:10.1680/ geot.1982.32.1.9]

Rowe, R.K., Davis, E.H., 1982b. The behaviour of anchor plates in sand. Geotechnique, 32(1):25-41. [doi:10.1680/ geot.1982.32.1.25]

Shahin, M.A., Jaksa, M.B., 2005. Neural network prediction of pullout capacity of marquee ground anchors. Computers and Geotechnics, 32(3):153-163. [doi:10.1016/j. compgeo.2005.02.003]

Shahin, M.A., Jaksa, M.B., 2006. Pullout capacity of small ground anchors by direct cone penetration test methods and neural networks. Canadian Geotechnical Journal, 43(6): 626-637. [doi:10.1139/t06-029]

Smola, A., Scholkopf, B., 1998. On a kernel based method for pattern recognition, regression, approximation and operator inversion. Algorithmica, 22(1-2):211-231. [doi:10. 1007/PL00013831]
Sutherland, H.B., 1988. Uplift resistance of soils. Geotechnique, 38(4):473-516.

Suykens, J.A.K., Lukas, L., van Dooren, P., et al., 1999. Least squares support vector machine classifiers: a large scale algorithm. Proceedings of European Conference Circuit Theory and Design, Stresa, Italy, p.839-842.

Suykens, J.A.K., de Barbanter, J., Lukas, L., et al., 2002. Weighted least squares support vector machines: robustness and sparse approximation. Neurocomputing, 48(1-4): 85-105. [doi:10.1016/S0925-2312(01)00644-0]

Tang, Y., Zang, Y.Q., Huang, G., et al., 2005. Granular SVM-RFE gene selection algorithm for reliable prostate cancer classification on microarray expression data. Proceedings of the 5th IEEE Symposium on Bioinformatics and Bioengineering, p.290-293. [doi:10.1109/ BIBE.2005.34]

Tao, B., Xu, W.J., Pang, G.B., et al., 2008. Prediction of bearing raceways superfinishing based on least squares support vector machines. Proceedings of the 4th International Conference on Natural Computation (ICNC), 2:125-129.

Vapnik, V.N., 1998. Statistical Learning Theory. Wiley, New York.

Vapnik, V.N., Lerner, A., 1963. Pattern recognition using generalized portrait method. Automation and Remote Control, 24:774-780.

Vermeer, P.A., Sutjiadi, W., 1985. The uplift resistance of shallow embedded anchors. Proceedings of the 11th International Conference Soil Mechanics and Foundation Engineering, San Francisco, p.1635-1638.

Vesic, A.S., 1971. Breakout resistance of objects embedded in ocean bottom. Journal of Soil Mechanics and Foundation Division, ASCE, 96(SM4):1311-1334.

\section{中文概要}

题 目: 基于最小二乘支持向量机算法的小地针抗拔承载 力研究

目 的：基于最小二乘支持向量机算法预测小地针的抗拔 承载力。

方 法: 最小二乘支持向量机算法中的输入参数包括等效 地针直径, 地针埋置深度, 平均顶椎阻力, 平均 椎套摩擦力以及安装工艺。使用现场试验的 119 组数据中的 83 组数据进行最小二乘支持向量机 回归模型分析, 并使用剩余的 36 组数据测试模 型的拟合良好性; 同时用敏感度分析研究每个输 入参数的作用。

结 论: 通过与人工神经网络模型的对比, 发现最小二乘 支持向量机的性能表现优异。

关键词: 人工神经网络法; 最小二乘支持向量机; 误差条; 地针; 抗拔承载力；现场试验；敏感度分析 